\title{
Can medicines development improve outcomes in asthma and chronic obstructive pulmonary disease management by driving effectiveness?
}

David A. Leather ${ }^{1 *}$ D, Louisa Yates ${ }^{1}$, Henrik Svedsater ${ }^{2}$, Loretta Jacques ${ }^{3}$, Susan Collier ${ }^{4}$, Danielle Powell ${ }^{1}$ and Rupert Jones ${ }^{5}$

\begin{abstract}
Despite the availability of treatment guidelines and inhaled medications for asthma and chronic obstructive pulmonary disease (COPD), much remains to be done to lessen the burden of these respiratory diseases for patients. The challenge of selecting effective and efficacious drugs for patients is a key focus area for healthcare professionals. Here we discuss the concept of "drivers of effectiveness" - features of a medicine which may increase or decrease its effectiveness in the presence of real-world factors - and highlight the importance of considering these drivers in the early stages of drug development, and exploring their impact in carefully designed pragmatic trials. Using the Salford Lung Studies (SLS) in asthma and COPD as an illustrative example, we discuss various features of the inhaled corticosteroid/long-acting $\beta_{2^{-}}$ agonist combination, fluticasone furoate/vilanterol (FF/NI), as potential drivers of effectiveness that may have contributed to the improved patient outcomes observed with initiation of FFNI versus continuation of usual care in the UK primary care setting.
\end{abstract}

Keywords: Asthma, Chronic obstructive pulmonary disease (COPD), Disease management, Effectiveness, Medicines development, Outcomes, Respiratory, Salford Lung Studies

\section{Background}

The worldwide burden of asthma and chronic obstructive pulmonary disease (COPD) remains high. The global state of progress in improving health outcomes for patients with asthma has largely plateaued and there has been little advancement towards helping a large proportion of patients whose asthma remains uncontrolled [1,2]. Similarly, COPD continues to be associated with high morbidity $[3,4]$ and according to 2016 World Health Organization estimates, COPD was the third leading cause of mortality worldwide [5]. Guidelines for the management of asthma and COPD have existed for, and evolved over, many decades. Likewise, effective medicines for asthma and COPD have been available for many years. Highly controlled efficacy studies, for example the Gaining Optimal Asthma ControL (GOAL)

\footnotetext{
* Correspondence: david.a.leather@gsk.com

${ }^{1}$ Global Respiratory Franchise, GlaxoSmithKline plc., Brentford, Middlesex, UK

Full list of author information is available at the end of the article
}

study [6], have demonstrated that good asthma control is possible in the majority of patients. Despite these evidencebased guidelines and medicines with proven efficacy in highly controlled clinical trials, we appear to be failing to make the headway we might expect in lessening the burden of respiratory diseases for patients.

The reasons for poor asthma control and lack of progress in asthma care have been widely described $[1,2,7-10]$. Haughney et al. [10] have defined some of the obstacles to achieving good asthma control (Table 1). Similar barriers have been described for COPD $[3,11]$.

While there is a strong evidence base supporting the efficacy of currently available medicines for asthma and COPD, their prescription by clinicians and use by patients is suboptimal and leaves many patients at risk due to poor disease control. Incorrectly prescribed and poorly utilized treatments are also costly and lead to inefficiency in healthcare systems. The challenge of selecting effective 
Table 1 Obstacles to achieving good asthma control

- Wrong diagnosis

- Incorrect choice of inhaler or poor technique

- Lifestyle choices (e.g. smoking)

- Co-morbidities (e.g. rhinitis, obesity)

- Individual variation in response to treatment

- Patient beliefs and adherence

and efficacious drugs for patients is a key focus area for healthcare professionals.

A medicine's efficacy is usually demonstrated under nearideal conditions in double-blind randomized controlled trials [DBRCTs]) [12]; such trials typically recruit highly selected patient populations and operate under experimental, highly monitored and controlled conditions, which may limit the generalizability of their findings to the broader disease population. Effectiveness can be thought of as the interaction of a medicine's proven efficacy with factors related to patients, actual medication use, and healthcare systems, which results in the effects observed in patients in the everyday clinical setting (Fig. 1). Abenhaim [13] has described the concept of "drivers of effectiveness" - features of a medicine that may increase or decrease the effectiveness of that medicine in the presence of real-world factors. These drivers of effectiveness encompass a range of factors relating to the patient, the medicine, and the environment, including: (i) patient acceptability, including perceived or real side effects and tolerability; (ii) the medicine's efficacy; (iii) persistence of correct use of the medicine; (iv) adherence; and (v) affordability, cost-effectiveness and economic factors, e.g. the price the patient may pay for medication and the patient's age. Other patient-related factors and factors relating to the healthcare system and medical practice, such as vaccination programs, self-management plans in asthma or outreach teams in COPD, may also impact a medicine's effectiveness and will clearly vary in different healthcare settings.

Abenhaim's team and the Innovative Medicines Initiative GetReal project have suggested that drivers of effectiveness should be considered early in the drug development cycle $[14,15]$ and that their impact be explored in appropriately designed studies alongside traditional DBRCTs. As DBRCTs are deliberately designed to remove potential confounders, they are unlikely to allow modifiers of effectiveness to be expressed. It is therefore important, as part of clinical development, that drugs are tested in their intended real-world setting, with minimal intervention (i.e. mimicking everyday clinical practice and preserving the usual behaviors of patients and healthcare professionals as closely as possible) in order to evaluate the medicine's true effectiveness. The inhaled corticosteroid (ICS)/long-acting $\beta_{2}$-agonist (LABA) combination, fluticasone furoate/vilanterol (FF/VI [Relvar]; GlaxoSmithKline plc.) was tested in a real-world effectiveness study program. The Salford Lung Studies (SLS) in asthma and COPD evaluated the effectiveness and safety of initiating once-daily inhaled FF/VI versus continuing usual maintenance inhaler therapy (usual care [UC]) in the UK

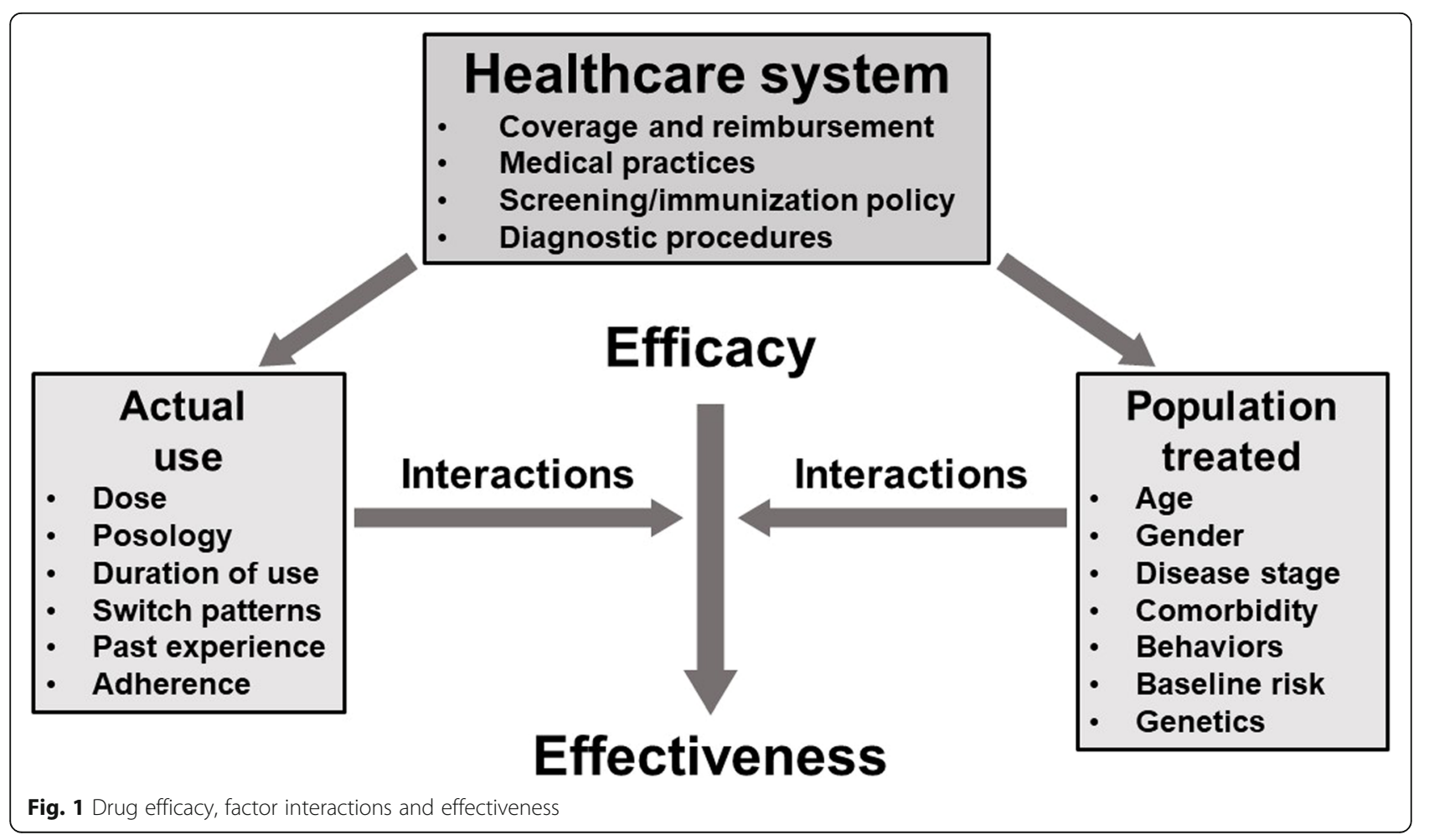


primary care setting. UC comprised a wide variety of inhaled and oral medicines as prescribed by each individual general practitioner (GP) taking part in the study and was not determined by protocol - a major difference compared with typical DBRCTs. The SLS designs and results have been published previously [16-20]. These open-label, pragmatic, randomized, controlled effectiveness trials demonstrated the benefits of initiating FF/VI versus continuing UC in terms of their respective primary endpoints of improvements in asthma control and reduction in COPD exacerbations [19, 20]. The studies were designed to enable GPs to function as study investigators, with changes in treatment during the study permitted based on their clinical opinions.

The results of the SLS raise the questions of what features were driving the improved effectiveness observed for FF/VI versus UC, and how could those drivers of effectiveness help to address some of the obstacles for improving care for patients with asthma and COPD?

\section{Potential drivers of effectiveness in asthma and COPD}

FF/VI delivered via the ELLIPTA dry powder inhaler was designed as an improvement over fluticasone propionate/ salmeterol delivered via the Diskus inhaler. An overview of factors thought to be important in driving clinical effectiveness is presented in Fig. 2. Various features of FF/VI could potentially have improved effectiveness and patient outcomes with initiation of FF/VI versus continuation of $\mathrm{UC}$ in the SLS, as discussed below.

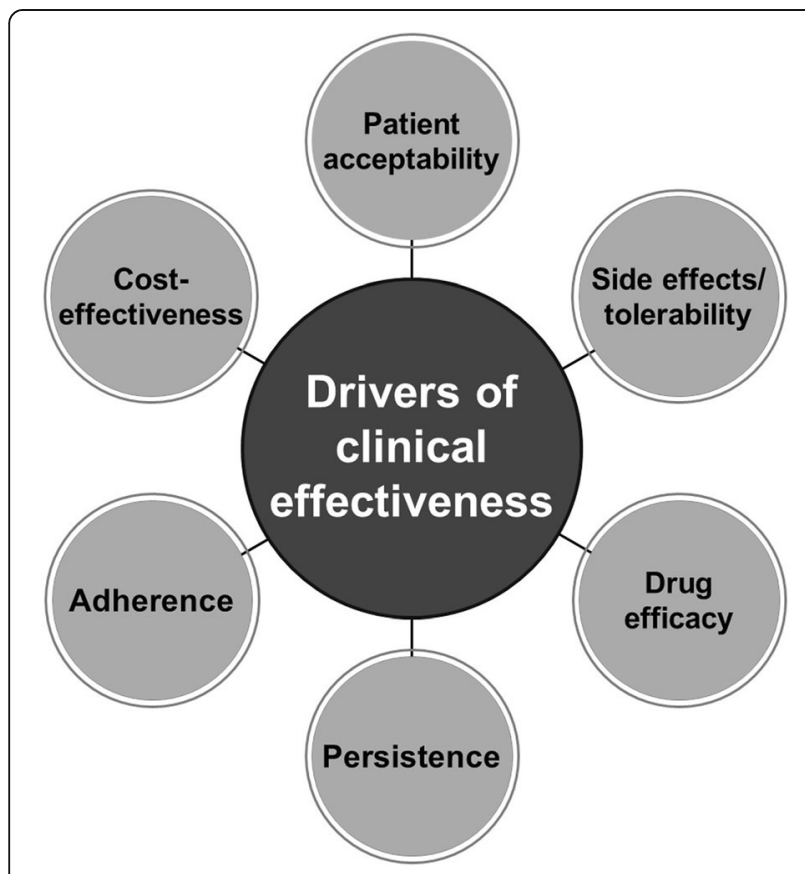

Fig. 2 Main drivers of clinical effectiveness

\section{Once-daily dosing}

Patient adherence with inhaled medications for the treatment of asthma and COPD is low [21, 22] for reasons including patient beliefs, side effects, dosing frequency, and poor inhaler technique [21-23].

In studies of adherence in the real-world setting, adherence rates have been reported to be as low as $10 \%$ and typically between 20 and 40\% [24-28].

Once-daily treatment administration has the potential to encourage/increase adherence compared with twice-daily administration, as evidenced in medications for asthma and other indications [29-31]. FF/VI was the first once-daily inhaled ICS/LABA combination to be broadly available worldwide. In the SLS, adherence was assessed using the Medication Adherence Report Scale for Asthma (MARSA) questionnaire and patients' prescription records were accessed through their electronic case report forms. The MARS-A was used to gather patients' patterns of medication use (e.g. "I only take it when I need it"), and the number of prescriptions issued was used to estimate the proportion of days covered (PDC) by study medication as a surrogate for treatment adherence. Both methods have their limitations: the MARS-A is a validated questionnaire to assess self-reported adherence, but self-reported behavior does not always reflect actual behavior, such as unintentional non-adherence. Furthermore, the measure captures patients' general tendencies of how they take their medication, not actual adherence per se. The use of prescribing data has considerable limitations in assessing adherence, as it only records the number of prescriptions issued, and not the number dispensed to, or actually used by, patients. Nevertheless, in SLS asthma, the reported mean PDC was 82.3\% for FF/VI and $78.2 \%$ for UC and in SLS COPD was $85.0 \%$ for FF/VI and $82.4 \%$ for UC [32, 33]. As planned, no statistical testing has been conducted on these data. Further assessment of adherence to FF/VI through electronic monitoring devices will aid better understanding of this driver of effectiveness [34-37].

\section{Rapid onset and long duration of action of the active molecules}

The rapid onset of action of a medication may result in a perceived benefit to the patient that may encourage treatment adherence [38]. A longer duration of action beyond the licensed dosing interval may mean that the medicine is more "forgiving" of the non-adherence commonly encountered in everyday practice (including irregular dosing and use) $[39,40]$. The onset and duration of action of FF/VI has been assessed in asthma. Studies evaluating the bronchodilator effects of FF/VI using serial lung function measures in asthmatic patients have demonstrated an onset of action as early as $15 \mathrm{~min}$ [41] and a 72-h duration of bronchodilation after a single dose [42]; slower in onset than formoterol (within 
minutes $[43,44])$ and longer in duration of action than formoterol or salmeterol (at least $12 \mathrm{~h}$ ) [43-45]. Bardsley et al. examined the duration of airway anti-inflammatory action of FF/VI by serially measuring fractional exhaled nitric oxide (FeNO) over a 14-day treatment period with FF/VI and over 21 days following cessation of therapy. Full suppression of FeNO in asthma was estimated to last for up to 3 days, with effective suppression continuing for up to 18 days, and improvements in forced expiratory volume in $1 \mathrm{~s}$ and peak expiratory flow lasting for 3-4 days after cessation of treatment [46]. While there are limited comparative data on the duration of anti-inflammatory action for ICS, separate studies in patients treated with budesonide have reported FeNO return to baseline values within 7 days of cessation of treatment [47].

\section{Device features and design}

Effective drug delivery systems enable the controlled introduction of a medicine into the body, while also improving drug efficacy and safety [48]. The dosage form and device can directly impact on treatment success and patient adherence [48]. Critical errors - those that can be defined as errors resulting in limited or no medication being delivered to the lung - have been associated with major impacts on respiratory symptoms and healthcare consumption $[49,50]$. The ELLIPTA inhaler has been shown to be superior to other commonly used inhalers for the administration of ICS/LABA medicines, in terms of patient preference for its design features of dose counter, ease of use, and dosing regimen [51]. Furthermore, it has been shown that fewer patients make critical errors with the ELLIPTA inhaler compared with a range of other ICS/ LABA inhalers, and that the ELLIPTA inhaler requires less teaching time than other inhalers [52]. In studies evaluating the dose delivery achieved through ELLIPTA, patients received a dose close to the label claim with inspiratory flow rates of $30 \mathrm{~L} / \mathrm{min}$ and above $30 \mathrm{~L} / \mathrm{min}$ peak inspiratory flow rate. Furthermore, studies have shown that asthma and COPD patients across a range of disease severities achieved a flow of $43 \mathrm{~L} / \mathrm{min}$ or above [53]. In everyday practice, a simple inhaler that requires less time to teach the correct technique, is easy to use, has a low potential for patients to make critical errors, delivers adequate dose across a broad range of inspiratory flow rates, and is preferred by patients, will be a positive driver of effectiveness since there will be greater confidence that the medication has been optimally delivered.

\section{Tolerability}

A theoretical consequence of some drivers of effectiveness is that, while the likelihood of correct and adequate dosing increases, the benefits in terms of positive outcomes might be outweighed by an increased risk of side effects. Tolerability and adverse events reported in phase lll clinical studies of FF/VI in patients with asthma and COPD were similar to those seen with the fluticasone propionate/salmeterol combination [54-56]. In the SLS, serious adverse event rates were very similar for FF/VI and UC $[19,20]$. Modeling studies have suggested that FF may have a better therapeutic index than other inhaled steroids [57].

\section{Discussion}

Asthma and COPD guidelines and regulatory and payer frameworks have long favored DBRCTs as constituting the highest level of evidence $[3,58]$. Although Cochrane highlighted the importance of understanding the effectiveness of medicines back in 1972 [12], his enthusiasm has not been broadly shared. Pragmatic real-world study designs have not been universally adopted and drug development has instead continued to focus on evaluating efficacy within highly controlled trials in highly selected patient populations. As a result, we are left struggling to assess the external validity of the results of such studies and medicine development programs. As well designed effectiveness studies are undervalued due to their pragmatic design features, the overriding focus on efficacy evaluation is likely to have hampered the implementation of drivers of effectiveness early in drug development processes.

The SLS were world-first, pragmatic, randomized, controlled trials conducted in the routine UK clinical practice setting to evaluate a pre-licensed inhaled medicine [16]. The trials were open-label to maintain their pragmatic design; however, this meant open-label for patients, GPs, pharmacists, other healthcare providers, and most of the study team. This could have introduced bias, particularly as FF/VI would have been either unlicensed or newly licensed while the studies were ongoing. In an attempt to minimise this bias, sponsor study team members who were involved in the development of the analysis plan and the actual data analyses were blinded to patients' individual therapies up until the formal unblinding of the studies, which occurred after the databases had been finalized. The SLS exemplify that by designing drivers of effectiveness into a medicine, the medicine alone can improve patient outcomes compared to other medications in the same drug class.

It is difficult to assess which components of the composite drivers of effectiveness play the biggest part in improving patient outcomes. Moreover, these drivers are likely to reinforce one another, whereby the physical features of the medicine are improving outcomes and, thus, patient-perceived benefits, which in turn may enhance the belief that the medicine is making a difference. For example, a longer duration of action of a medicine is likely to mitigate any sub-optimal adherence, thus 
altering the impact of the latter on actual and perceived symptom control. Likewise, an easy-to-use inhaler would enhance the likelihood that the medicine is inhaled correctly, which would increase its effectiveness, as measured and as perceived by patients. We suggest that further work in this field should be pursued for guiding drug developers to design better medicines. We also suggest that regulators, guideline writers, and payers should seek to understand the now well-established concept of effectiveness and build it into their frameworks.

Traditional DBRCTs are deliberately designed to remove potential confounders such as device and patient preference, and thus are unlikely to allow modifiers of effectiveness to be expressed. Such trials rely on highly selected patient populations chosen for their compliance with treatment and study visits, who are typically socially stable, and have high adherence and near-perfect inhaler technique; these patients are not representative of patients seen in everyday clinical practice. Trials such as the SLS show that patients in primary care, recruited with minimal exclusion criteria, can participate in a randomized controlled trial and yield data that complement the data obtained in traditional efficacy DBRCTs.

Currently, we may be ignoring a crucial aspect of medicine assessment and, therefore, denying patients the opportunity for more effective therapies, while also discouraging effectiveness and patient-focused medicine development.

\section{Conclusions}

Evidence suggests that it is possible to design medicines to include a composite of features that can drive effectiveness. Improving a medicine's effectiveness can provide a meaningful impact on patient outcomes, which can be demonstrated through appropriately designed pragmatic clinical trials. It is time to reconsider evidence hierarchies and bring more external validity to them. This is ultimately likely to benefit patients through encouraging patient-focused drug development, which includes consideration of the drivers of effectiveness and making more effective medicines available to patients.

\section{Abbreviations}

COPD: Chronic obstructive pulmonary disease; DBRCTs: Double-blind randomized controlled trials; FeNO: Fractional exhaled nitric oxide; FFNl: Fluticasone furoate/vilanterol; GP: General practitioner; ICS: Inhaled corticosteroid; LABA: Long-acting $\beta_{2}$-agonist; MARS-A: Medication Adherence Report Scale for Asthma; PDC: Proportion of days covered; SLS: Salford Lung Studies; UC: Usual care

\section{Acknowledgments}

Editorial support in the development of this manuscript (in the form of editorial suggestions to draft versions, assembling tables and figures, collating author comments, grammatical editing, and referencing) was provided by Emma Landers, PhD, at Gardiner-Caldwell Communications (Macclesfield, UK), and was funded by GlaxoSmithKline plc.

Trade marks are the property of their respective owners.

\section{Authors' contributions}

DAL: Study conception/design, data analysis/interpretation, manuscript writing/review and approval of the final version to be submitted. LY: Data analysis/interpretation, manuscript writing/review and approval of the final version to be submitted. HS: Study conception/design, data analysis/interpretation, manuscript writing/review and approval of the final version to be submitted. $\sqcup$ : Data analysis/interpretation, manuscript writing/review and approval of the final version to be submitted. SC: Study conception/design, data acquisition, data analysis/interpretation, manuscript writing/review and approval of the final version to be submitted. DP: Data analysis/interpretation, manuscript writing/review and approval of the final version to be submitted. R: Data analysis/interpretation, manuscript writing/review and approval of the final version to be submitted.

\section{Funding}

SLS COPD (HZC115151; NCT01551758) and SLS asthma (HZA115150; NCT01706198) were funded by GlaxoSmithKline plc. RJ acknowledges support from the National Institute for Health Research (NIHR) Collaboration for Leadership in Applied Health Research and Care of the South West Peninsula (PenCLAHRC) in the UK.

\section{Availability of data and materials}

Anonymized individual participant data from this study plus the annotated case report form, protocol, reporting and analysis plan, data set specifications, raw dataset, analysis-ready dataset, and clinical study report are available for research proposals approved by an independent review committee. Proposals should be submitted to www.clinicalstudydatarequest. com. A data access agreement will be required.

\section{Ethics approval and consent to participate}

The Salford Lung Study protocols were approved by the National Research Ethics Service Committee North West, Greater Manchester South (approval numbers 12/NW/0455 and 11/NW/0798). All patients provided written informed consent for participation.

\section{Consent for publication}

All authors have contributed to the writing and/or critical review of this manuscript and all have approved the final version for submission for publication.

\section{Competing interests}

DAL, LY, HS, LJ, SC, and DP disclose employment with, and stock/share ownership in, GlaxoSmithKline plc. RJ has received grants from AstraZeneca and GlaxoSmithKline plc., and personal fees from AstraZeneca, Boehringer Ingelheim, Chiesi, GlaxoSmithKline plc., Novartis, Nutricia and Pfizer outside the submitted work.

\section{Author details}

${ }^{1}$ Global Respiratory Franchise, GlaxoSmithKline plc., Brentford, Middlesex, UK. ${ }^{2}$ Value Evidence \& Outcomes, GlaxoSmithKline plc., Brentford, Middlesex, UK. ${ }^{3}$ Clinical Sciences, GlaxoSmithKline plc., Uxbridge, Middlesex, UK. ${ }^{4}$ UK Medical, GlaxoSmithKline plc., Uxbridge, Middlesex, UK. ${ }^{5}$ Community and Primary Health Care, Faculty of Medicine and Dentistry, Plymouth University,

Plymouth, UK.

Received: 14 January 2019 Accepted: 8 July 2019

Published online: 02 August 2019

References

1. Asthma UK. Falling through the gaps: why more people need basic asthma care. Annual Asthma Survey 2017 Report. 2017. Available at: https://www. asthma.org.uk/globalassets/get-involved/external-affairs-campaigns/ publications/annual-asthma-care-survey/annual-asthma-survey-2017/ asthmauk-annual-survey-2017.pdf. Last accessed 16 May 2019.

2. Ebmeier S, Thayabaran D, Braithwaite I, Bénamara C, Weatherall M, Beasley R. Trends in international asthma mortality: analysis of data from the WHO mortality database from 46 countries (1993-2012). Lancet. 2017;390:935-45.

3. Global Initiative for Chronic Obstructive Lung Disease (GOLD) 2019 report. Global strategy for the diagnosis, management and prevention of chronic obsructive pulmonary disease. Available at: https://goldcopd.org/. Last accessed 10 June 2019. 
4. GBD 2015 Chronic Respiratory Disease Collaborators. Global, regional, and national deaths, prevalence, disability-adjusted life years, and years lived with disability for chronic obstructive pulmonary disease and asthma, 19902015: a systematic analysis for the Global Burden of Disease Study 2015. Lancet Respir Med. 2017;5:691-706.

5. World Health Organization Global Health Estimates 2016: Deaths by cause, age, sex, by country and by region. 2000-2016. Geneva, World Health Organization; 2018. Available at: http://www.who.int/news-room/factsheets/detail/the-top-10-causes-of-death. Last accessed 16 May 2019.

6. Bateman ED, Boushey HA, Bousquet J, Busse WW, Clark TJ, Pauwels RA, Pedersen SE, GOAL Investigators Group. Can guideline-defined asthma control be achieved? The Gaining Optimal Asthma ControL study. Am J Respir Crit Care Med. 2004;170:836-44.

7. Kersul A, Balmes S, Rodríguez N, Torrego A. Asthma control. Possible obstacles along the way. Arch Bronconeumol. 2010;46(Suppl 6):8-13.

8. Horne R, Price D, Cleland J, Costa R, Covey D, Gruffydd-Jones K, Haughney J, Henrichsen SH, Kaplan A, Langhammer A, Østrem A, Thomas M, van der Molen T, Virchow JC, Williams S. Can asthma control be improved by understanding the patient's perspective? BMC Pulm Med. 2007;7:8.

9. Barnes PJ. Achieving asthma control. Curr Med Res Opin. 2005;21(Suppl 4): S5-9.

10. Haughney J, Price D, Kaplan A, Chrystyn H, Horne R, May N, Moffat M, Versnel J, Shanahan ER, Hillyer EV, Tunsäter A, Bjermer L. Achieving asthma control in practice: understanding the reasons for poor control. Respir Med. 2008;102:1681-93.

11. Russell S, Ogunbayo OJ, Newham JJ, Heslop-Marshall K, Netts P, Hanratty B, Beyer F, Kaner E. Qualitative systematic review of barriers and facilitators to self-management of chronic obstructive pulmonary disease: views of patients and healthcare professionals. NPJ Prim Care Respir Med. 2018;28:2.

12. Cochrane AL. Effectiveness and efficiency: random reflections on health services: Nuffield Provincial Hospitals Trust; 1972.

13. IMI GetReal Initiative. Drivers of effectiveness. Available at: https://rwenavigator.eu/clarify-the-issues/drivers-of-effectiveness/. Last accessed 16 May 2019.

14. Nordon C, Karcher H, Pichler F, Abenhaim L. Efficacy, effectiveness and the "efficacy-to-effectiveness gap": review of the current state of play and perspectives. First results from the IMI GetReal Consortium. Value Health. 2014;17:A586.

15. IMI GetReal Initiative. Report WP2 broadcast 'Introduction to the concept of drivers of effectiveness'. 18 April 2016. Available at: http://www.imi-getreal. eu/News/ID/41/Report-WP2-broadcast-Introduction-to-the-Concept-ofDrivers-of-Effectiveness. Last accessed 16 May 2019.

16. New JP, Bakerly ND, Leather D, Woodcock A. Obtaining real-world evidence: the Salford Lung Study. Thorax. 2014;69:1152-4.

17. Bakerly ND, Woodcock A, New JP, Gibson JM, Wu W, Leather D, Vestbo J. The Salford Lung Study protocol: a pragmatic, randomised phase III realworld effectiveness trial in chronic obstructive pulmonary disease. Respir Res. 2015;16:101.

18. Woodcock A, Bakerly ND, New JP, Gibson JM, Wu W, Vestbo J, Leather D. The Salford Lung Study protocol: a pragmatic, randomised phase III realworld effectiveness trial in asthma. BMC Pulm Med. 2015;15:160.

19. Woodcock A, Vestbo J, Bakerly ND, New J, Gibson JM, McCorkindale S, Jones R, Collier S, Lay-Flurrie J, Frith L, Jacques L, Fletcher JL, Harvey C, Svedsater H, Leather D, Salford Lung Study Investigators. Effectiveness of fluticasone furoate plus vilanterol on asthma control in clinical practice: an open-label, parallel group, randomised controlled trial. Lancet. 2017;390:2247-55.

20. Vestbo J, Leather D, Diar Bakerly N, New J, Gibson JM, McCorkindale S, Collier S, Crawford J, Frith L, Harvey C, Svedsater H. Woodcock A, Salford Lung Study investigators. Effectiveness of fluticasone furoate-vilanterol for COPD in clinical practice. N Engl J Med. 2016;375:1253-60.

21. Dekhuijzen R, Lavorini F, Usmani OS, van Boven JFM. Addressing the impact and unmet needs of nonadherence in asthma and chronic obstructive pulmonary disease: where do we go from here? J Allergy Clin Immunol Pract. 2018;6:785-93.

22. Rogliani P, Ora J, Puxeddu E, Matera MG, Cazzola M. Adherence to COPD treatment: myth and reality. Respir Med. 2017;129:117-23.

23. Mäkelä MJ, Backer V, Hedegaard M, Larsson K. Adherence to inhaled therapies, health outcomes and costs in patients with asthma and COPD. Respir Med. 2013;107:1481-90.

24. Breekveldt-Postma NS, Koerselman J, Erkens JA, van der Molen T, Lammers JW, Herings RM, CAMERA Study Group Members. Treatment with inhaled corticosteroids in asthma is too often discontinued. Pharmacoepidemiol Drug Saf. 2008;17:411-22.

25. Janson C, de Marco R, Accordini S, Almar E, Bugiani M, Carolei A, Cazzoletti L, Cerveri I, Corsico A, Duran-Tauleria E, Gislason D, Gulsvik A, Jõgi R, Marinoni A, Martínez-Moratalla J, Pin I, Vermeire P, Jarvis D. Changes in the use of anti-asthmatic medication in an international cohort. Eur Respir J. 2005;26:1047-55.

26. Adams RJ, Fuhlbrigge A, Guilbert T, Lozano P, Martinez F. Inadequate use of asthma medication in the United States: results of the asthma in America national population survey. J Allergy Clin Immunol. 2002;110:58-64.

27. Ställberg B, Nyström Kronander U, Olsson P, Gottberg L, Rönmark E, Lundbäck B. Living with asthma in Sweden--the ALMA study. Respir Med. 2003;97:835-43.

28. de Marco R, Cazzoletti L, Cerveri I, Corsico A, Bugiani M, Accordini S, Carrozzi L, Dallari R, De Togni A, Marinoni A, Pirina P, Janson C, ISAYA Study Group. Are the asthma guideline goals achieved in daily practice? A population-based study on treatment adequacy and the control of asthma. Int Arch Allergy Immunol. 2005;138:225-34.

29. Falagas ME, Karagiannis AK, Nakouti T, Tansarli GS. Compliance with oncedaily versus twice or thrice-daily administration of antibiotic regimens: a meta-analysis of randomized controlled trials. PLoS One. 2015;10:e0116207.

30. Laliberte F, Bookhart BK, Nelson WW, Lefebvre P, Schein JR, RondeauLeclaire J, Duh MS. Impact of once-daily versus twice-daily dosing frequency on adherence to chronic medications among patients with venous thromboembolism. Patient. 2013:6:213-24.

31. Price D, Robertson A, Bullen K, Rand C, Horne R, Staudinger H. Improved adherence with once-daily versus twice-daily dosing of mometasone furoate administered via a dry powder inhaler: a randomized open-label study. BMC Pulm Med. 2010;10:1.

32. GlaxoSmithKline plc. GSK Clinical Study Register. Study HZA115150 Clinica Study Report. Available at: https://s3.amazonaws.com/ctr-gsk-7381/11515 0/6445927f-953c-402f-a79a-6ca22d93169c/e1e0596f-8dc8-4212-9e04-ce2 a778d0e6d/gsk-115150-clinical-study-report-redact-v1.pdf. Last accessed 16 May 2019.

33. Collier S, Browning D, New JP, Gibson JM, Stephens L, Diar Bakerly N, Fletcher J, Crawford J. Describing adherence data in a clinical effectiveness trial: the Salford Lung Study in COPD (SLS COPD). Thorax. 2017;72:Suppl 3, abstract P269. Poster presented at the British Thoracic Society Winter Meeting 2017

34. Stanford RH, Averell C, Parker ED, Blauer-Peterson C, Reinsch TK, Buikema AR. Assessment of adherence and asthma medication ratio for a once-daily and twice-daily inhaled corticosteroid/long-acting $\beta$-agonist for asthma. J Allergy Clin Immunol Pract. 2019;7:1488-96.

35. Averell C, Stanford R, Laliberte F, Wu J, Germain G, Duh MD. Adherence with once-daily fluticasone furoate/vilanterol compared to twice-daily budesonide/formoterol or fluticasone propionate/salmeterol in asthma. Ann Allergy Asthma Immunol. 2018;121(5):Suppl:P204.

36. Atsuta R, Takai J, Mukai I, Kobayashi A, Ishii T, Svedsater H. Patients with asthma prescribed once-daily fluticasone furoate/vilanterol or twice-daily fluticasone propionate/salmeterol as maintenance treatment: analysis from a claims database. Pulm Ther. 2018:4:135-47.

37. Stanford RH, Parker ED, Reinsch TK, Buikema AR, Blauer-Peterson C. Assessment of COPD-related outcomes in patients initiating a once daily or twice daily ICS/LABA. Respir Med. 2019;150:1-7.

38. Cazzola M, Beeh KM, Price D, Roche N. Assessing the clinical value of fast onset and sustained duration of action of long-acting bronchodilators for COPD. Pulm Pharmacol Ther. 2015;31:68-78.

39. Urquhart J. Patient non-compliance with drug regimens: measurement, clinical correlates, economic impact. Eur Heart J. 1996;17(Suppl A):8-15.

40. Assawasuwannakit P, Braund R, Duffull SB. Quantification of the forgiveness of drugs to imperfect adherence. CPT Pharmacometrics Syst Pharmacol. 2015:4:e00004

41. GlaxoSmithKline plc. Relvar ELLIPTA. Summary of product characteristics. Available at: http://www.ema.europa.eu/docs/en_GB/document_library/ EPAR_-_Product_Information/human/002673/WC500157633.pdf. Last accessed 16 May 2019

42. Braithwaite I, Williams M, Power S, Pilcher J, Weatherall M, Baines A, Moynihan J, Kempsford R, Beasley R, FF/NI study team. Randomised, doubleblind, placebo-controlled, cross-over single dose study of the bronchodilator duration of action of combination fluticasone furoate/ vilanterol inhaler in adult asthma. Respir Med. 2016;119:115-21. 
43. Lötvall J. Pharmacological similarities and differences between beta2agonists. Respir Med. 2001;95(Suppl B):S7-11.

44. Symbicort Turbohaler 200/6 Inhalation powder. Summary of product characteristics. Available at: https://www.medicines.org.uk/emc/product/132 7/smpc\#PHARMACOLOGICAL_PROPS. Last accessed 16 May 2019.

45. Seretide Accuhaler 50 microgram/100 microgram/dose inhalation powder, pre-dispensed. Summary of product characteristics. Available at: https:// www.medicines.org.uk/emc/product/5504/smpc\#PHARMACOLOGICAL_ PROPS. Last accessed 16 May 2019.

46. Bardsley G, Daley-Yates P, Baines A, Kempsford R, Williams M, Mallon T, Braithwaite I, Riddell K, Joshi S, Bareille P, Beasley R, Fingleton J, study team. Anti-inflammatory duration of action of fluticasone furoate/vilanterol trifenatate in asthma: a cross-over randomised controlled trial. Respir Res. 2018;19:133.

47. Kharitonov SA, Donnelly LE, Montuschi P, Corradi M, Collins JV, Barnes PJ. Dose-dependent onset and cessation of action of inhaled budesonide on exhaled nitric oxide and symptoms in mild asthma. Thorax. 2002;57:889-96.

48. Bruschi ML. (ed) Strategies to modify the drug release from pharmaceutical systems. (Woodhead Publishing Limited, Elsevier, 2015).

49. Melani AS, Bonavia M, Cilenti V, Cinti C, Lodi M, Martucci P, Serra M, Scichilone N, Sestini P, Aliani M, Neri M, Gruppo Educazionale Associazione Italiana Pneumologi Ospedalieri. Inhaler mishandling remains common in real life and is associated with reduced disease control. Respir Med. 2011; 105:930-8.

50. Kocks JWH, Chrystyn H, van der Palen J, Thomas M, Yates L, Landis SH Driessen MT, Gokhale M, Sharma R, Molimard M. Systematic review of association between critical errors in inhalation and health outcomes in asthma and COPD. NPJ Prim Care Respir Med. 2018;28:43.

51. Kirby SY, Zhu CQ, Kerwin EM, Stanford RH, Georges G. A randomized controlled trial comparing two dry powder inhalers: more patients with COPD prefer ELLIPTA compared to DISKUS based on device-specific attributes. Am J Respir Crit Care Med. 2014;189:A3037.

52. van der Palen J, Thomas M, Chrystyn H, Sharma RK, van der Valk PD, Goosens M, Wilkinson T, Stonham C, Chauhan AJ, Imber V, Zhu CQ Svedsater H, Barnes NC. A randomised open-label cross-over study of inhaler errors, preference and time to achieve correct inhaler use in patients with COPD or asthma: comparison of ELLIPTA with other inhaler devices. NPJ Prim Care Respir Med. 2016;26:16079.

53. Prime D, de Backer W, Hamilton M, Cahn A, Preece A, Kelleher D, Baines A, Moore A, Brealey N, Moynihan J. Effect of disease severity in asthma and chronic obstructive pulmonary disease on inhaler-specific inhalation profiles through the ELLIPTA ${ }^{\oplus}$ dry powder inhaler. J Aerosol Med Pulm Drug Deliv. 2015;28:1-12.

54. Agustí A, de Teresa L, De Backer W, Zvarich MT, Locantore N, Barnes N, Bourbeau J, Crim C. A comparison of the efficacy and safety of once-daily fluticasone furoate/vilanterol with twice-daily fluticasone propionate/ salmeterol in moderate to very severe COPD. Eur Respir J. 2014:43:763-72.

55. Bernstein D, Andersen L, Forth R, Jacques $L$, Yates L. Once-daily fluticasone furoate/vilanterol versus twice-daily fluticasone propionate/salmeterol in patients with asthma well controlled on ICS/LABA. J Asthma. 2018;13:1-10.

56. Woodcock A, Bleeker ER, Lötvall J, O'Byrne PM, Bateman ED, Medley H, Ellsworth A, Jacquees L, Busse WW. Efficacy and safety of fluticasone furoate/vilanterol compared with fluticasone propionate/salmeterol combination in adult and adolescent patients with persistent asthma: a randomized trial. Chest. 2013;144:1222-9.

57. Daley-Yates PT. Inhaled corticosteroids: potency, dose equivalence and therapeutic index. Br J Clin Pharmacol. 2015;80:372-80.

58. Global Initiative for Asthma. Global Strategy for Asthma Management and Prevention, 2019. Available from: https://ginasthma.org/wp-content/uploads/201 9/06/GINA-2019-main-report-June-2019-wms.pdf. Last accessed 16 July 2019.

\section{Publisher's Note}

Springer Nature remains neutral with regard to jurisdictional claims in published maps and institutional affiliations.

Ready to submit your research? Choose BMC and benefit from:

- fast, convenient online submission

- thorough peer review by experienced researchers in your field

- rapid publication on acceptance

- support for research data, including large and complex data types

- gold Open Access which fosters wider collaboration and increased citations

- maximum visibility for your research: over $100 \mathrm{M}$ website views per year

At BMC, research is always in progress.

Learn more biomedcentral.com/submissions 